\title{
KONTROL PENGOBATAN OPTIMAL PADA MODEL PENYEBARAN TUBERKULOSIS TIPE SEIT
}

\author{
Jonner Nainggolan \\ Jurusan Matematika - Universitas Cenderawasih [Email: jonn_cesil@yahoo.co.id]
}

\begin{abstract}
A tuberculosis model of SEIT type which incorporates treatment of infectives is considered. The population is divided into four compartments, that is: $S$ are individuals in the susceptible compartment, $E$ are individuals in the exposed compartments, $I$ are individuals in the infected compartment, and $T$ are individuals in the treatment compartments. For this model, controls on treatment is incorporated to reduce the actively infected individual compartments, via application of the Pontryagins Maximum Principle of optimal control theory. Numerical calculations with the approach of the Runge-Kutta method of fourth order can be seen that, the influence of the control treatment to more effectively reduce the number of individuals in the infected compartment compared with no controls. The basic reproduction ratio with control less compared with no controls.
\end{abstract}

Keywords: Optimal control, tuberculosis, treatment, SEIT type, the basic reproduction ratio.

\section{PENDAhuluan}

Tuberkulosis merupakan penyakit yang disebakan oleh oleh bakteri Mycobacterium tuberculosis dan merupakan penyakit infeksi kronis menular yang menjadi masalah kesehatan dan perhatian dunia (Crofton dkk., 2002). Tuberkulosis (TB) merupakan penyakit yang membunuh hampir $2-3$ juta masyarakat di dunia per tahun.

WHO meluncurkan suatu rencana strategis global (tahun 2006-2015) yang bertujuan untuk: (1) Meningkatkan dan memperluas pemanfaatan strategi untuk menghentikan penularan penyakit tuberkulosis dengan cara meningkatkan akses terhadap diagnosis yang akurat untuk mencapai target global dalam pengendalian penyakit tuberkulosis, dan (2) Mempercepat upaya eliminasi penyakit tuberkulosis dengan cara meningkatkan penelitian dan pengembangan untuk berbagai alat diagnostik, obat dan vaksin baru, serta meningkatkan penerapan metode baru dan menjamin pemanfaatan, akses dan pencapaian.

Individu yang terinfeksi penyakit tuberkulosis aktif yaitu individu yang dapat menularkan penyakit ke individu kelompok lain, sedangkan individu yang terinfeksi penyakit tuberkulosis pasif yaitu individu yang belum dapat menularkan penyakit ke individu kompartemen lain (Crofton et al., 2002).

Penanggulangan individu yang terinfeksi penyakit tuberkulosis pasif dapat dilakukan dengan chemoprophylaxis dengan cara memberikan Obat Anti Tuberkulosis (OAT) isoniazid (Crofton dkk., 2002). Sedangkan untuk menanggulangi individu yang sudah terinfeksi penyakit tuberkulosis aktif, WHO telah merekomendasikan untuk memberikan OAT: isonizid, rifampisin, pirazinamid, etambutol, dan streptomosin untuk diimplementasikan secara bertahap keseluruh unit pelayanan kesehatan di dunia (Crofton dkk., 2002). Pengendalian penyebaran suatu penyakit dapat dilakukan dengan pengobatan (Gerberding dkk., 2003; Crofton dkk., 2002). Pengobatan terhadap suatu penyakit yang pasif dengan chemoprophylaxis (David dkk., 2000).

Model dinamika pengobatan terhadap penyakit tuberkulosis telah dikaji oleh CastilloChavez dan Feng (1997), Model chemoprophylaxis dan pengobatan transmisi tuberkulosis dikaji oleh Bhunu dkk. (2008).

Terjadinya endemik suatu penyakit dapat dilihat dari nilai the reproduction ratio dari 
model dinamik penyakit tersebut, keadaan bebas penyakit stabil secara lokal jika the reproduction ratio $<1$, dan jika the reproduction ratio $>1$ maka penyakit akan menyebar (Driessche dan Watmough, 2002).

Model matematika mempunyai peranan penting untuk menganalisis penyebaran dan mengontrol suatu penyakit menular. Pengendalian penyebaran suatu epidemik dapat diberikan kontrol optimal telah dikaji oleh Neilan dan Lenhart (2010), pengendalian transmisi tuberkulosis dengan kontrol chemoprophylaxis dan pengobatan telah dikaji oleh Agusto (2008). Pada paper ini mengkaji kontrol optimal pada penyakit tuberkulosis dari model reinfeksi exogenous pada persamaan (20)(23) paper yang dikaji oleh Castillo-Cavez dan Song (2004). Kontrol yang diberikan adalah kontrol pengobatan optimal dalam upaya menurunkan jumlah individu kompartemen terinfeksi dan meningkatkan jumlah individu kompartemen pengobatan. Penyelesaian kontrol optimal yang digunakan dengan pendekatan Prinsip Maksimum Pontryagin. Terakhir diberikan simulasi numerik dengan menggunakan metode Runge-Kutta orde empat.

\section{MODEL PENYEBARAN TUBERKULO- SIS TIPE SEIT}

Model kontrol optimal yang dikaji dari model transmisi penyebaran penyakit tuberkulosis dari model transmisi penyakit tuberkulosis (Castillo-Cavez dan Song, 2004). Populasi pada model dinamik epidemik yang dikaji dibagi menjadi 4 kompartemen yaitu sebagai berikut: Individu yang masih sehat dan rentan terinfeksi penyakit tuberkulosis masuk ke dalam kompartemen susceptible pada waktu $t$ dinotasikan dengan $S(t)$. Individu terinfeksi pasif (laten) yang belum dapat menularkan penyakit ke individu yang lain masuk ke dalam kompartemen exposed pada waktu $t$ dinotasikan dengan $E(t)$. Individu terinfeksi aktif yang dapat menularkan ke individu yang lain masuk ke dalam kompartemen infected pada waktu $t$ dinotasikan dengan $I(t)$. Kemudian Individu yang sudah sembuh karena pengobatan masuk ke dalam kompartemen pengobatan pada waktu $t$ dinotasikan dengan $T(t)$.

Individu rekruitmen masuk ke dalam kompartemen susceptible dengan laju $\Lambda$. Individu susceptible yang kontak dengan individu terinfeksi dengan laju infeksi $\lambda=\frac{c \beta I}{N}$.

Total populasi merupakan jumlah dari semua kompartemen- kompartemen yaitu: $N(t)$ $=S(t)+E(t)+I(t)+T(t)$. Setiap kompartemen mengalami kematian secara alamiah sebesar $\mu$, dan meninggal karena sakit dengan laju $d$. Kompartemen Kompartemen susceptible yang kontak dengan $I$ dengan laju $\beta$ masuk ke $E$. Individu yang terinfeksi diobati dengan laju $r$ masuk ke kompartemen $T$. Sedangkan kompartemen $T$ yang kontak lagi dengan $I$ terinfeksi kembali dengan laju $\sigma$. Adapun diagram alur model tipe SEIT yang dikaji oleh Castillo-Cavez dan Song (2004) dengan memperhatikan reinfeksi dapat dilihat seperti Gambar 1.

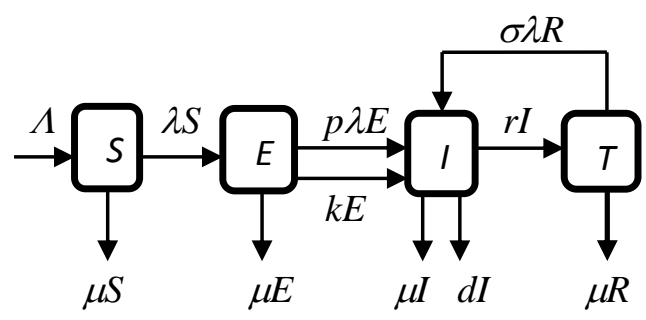

Gambar 1. Dinamika transmisi penyakit tuberkulosis tipe SEIT

Berdasarkan Gambar 1 dapat dinyatakan dalam persamaan berikut:

$$
\begin{aligned}
& \frac{d S}{d t}=\Lambda-\lambda S-\mu S \\
& \frac{d E}{d t}=\lambda S-p \lambda E-(k+\mu) E \\
& \frac{d I}{d t}=p \lambda E+k E-(\mu+d+r) I+\sigma \lambda R \\
& \frac{d T}{d t}=r I-\sigma \lambda R-\mu R
\end{aligned}
$$

dimana parameter-parameter $\Lambda, c, \beta, \mu, p, k$, $\sigma, d, r \geq 0$ dan jumlah awal kompartemenkompartemen $S(0)=S_{0} \geq 0, E(0)=E_{0} \geq 0, I(0)$ $=I_{0} \geq 0, T(0)=T_{0} \geq 0$, bentuk $\lambda=\frac{c \beta I}{N}$ reinfeksi exogeneous. 


\subsection{Analisis Model Transmisi Tuberkulosis \\ Tipe $S E I T$}

Pada analisis epidemiologi tipe SEIT ditentukan titik ekuilibrium dan basic reproduction ratio. Titik ekuilibrium nonendemik dari persamaan (1) diperoleh pada waktu laju masing-masing kompartemen sama dengan nol dan jumlah individu kompartemen terinfeksi sama dengan nol. Titik ekuilibrium non-endemik dari persamaan (1) adalah (Perko, 1991)

$$
E_{0}=\left(S_{0}, E_{0}, I_{0}, T_{0}\right)=\left(\frac{\Lambda}{\mu}, 0,0,0\right) .
$$

Titik ekuilibrium endemik persamaan (1) adalah (Perko, 1991)

$$
E_{1}=\left(\frac{\Lambda}{\mu+\lambda}, \frac{\lambda \lambda}{(\mu+\lambda)(p \lambda+k+\mu)}, \frac{\lambda N}{c \beta}, \frac{r \lambda N}{c \beta(\mu+\sigma \lambda)}\right) .
$$

Basic reproduction ratio persamaan diperoleh dengan menggunakan Next Generation Matrix (Driessche danWatmough, 2002)

$$
\mathfrak{R}_{0}=\frac{c \beta \mu \Lambda}{\mu N(\mu+k)(\mu+r+d)} .
$$

\section{Teorema 1}

Titik ekuilibrium endemik $E_{0}$ bersifat stabil secara lokal jika $\Re_{0}<1$ dan tidak stabil jika $\Re_{0}>1$.

Bukti:

Pelinearan matriks Jacobian model (1) di titik ekuilibrium $E_{0}$. Matriks Jacobi $J_{E_{0}}$ ekuilibrium non-endemik adalah

$$
J_{E_{0}}=\left[\begin{array}{cccc}
-\mu & 0 & -\frac{c \beta \Lambda}{\mu N} & 0 \\
0 & -k-\mu & \frac{c \beta \Lambda}{\mu N} & 0 \\
0 & k & -\mu-r-d & 0 \\
0 & 0 & r & -\mu
\end{array}\right] .
$$

Titik ekuilibrium non-endemik $E_{0}$ stabil secara lokal jika semua nilai eigen $\operatorname{dari} \operatorname{Det}\left(J_{E_{0}}-\lambda\right)=0$ bernilai real negatif (Perko, 1991; Brauer and Castillo-Chavez, 2000). Nilai eigen dari $\operatorname{Det}\left(J_{E_{0}}-\lambda\right)=0$ semua bernilai negatif untuk $c \beta \mu \Lambda<\mu N(\mu+k)(\mu+r+d), \quad$ ekivalen dengan $\mathfrak{R}_{0}<1$. Sebaliknya nilai eigen dari
$\operatorname{Det}\left(J_{P_{0}}-\lambda\right)=0$, jika terdapat salah satu yang bernilai real positif jika $\mathfrak{R}_{0}>1$ dengan kata lain $E_{0}$ tidak stabil.

\subsection{Kontrol Pengobatan Optimal Pada Transmisi Tuberkulosis}

Pada persamaan (1) diberikan variabel kontrol $U=\{u \mid u(t)$ terbatas dan terukur, $\left.0 \leq u(t) \leq b \leq 1, \quad t \in\left[0, t_{f}\right]\right\}, \quad$ dimana $u(t)$ adalah kontrol pengobatan per unit waktu. Persamaan epidemiologi tipe SEIT setelah diberikan kontrol pengobatan $(u)$ persamaan (1) menjadi

$$
\begin{aligned}
& \frac{d S}{d t}=\Lambda-\lambda S-\mu S \\
& \frac{d E}{d t}=\lambda S-p \lambda E-(k+\mu) E \\
& \frac{d I}{d t}=p \lambda E+k E-(\mu+d+r(1+u)) I+\sigma \lambda R \\
& \frac{d T}{d t}=r(1+u) I-\sigma \lambda R-\mu R
\end{aligned}
$$

Berdasarkan persamaan (3) dengan menggunakan operator Next Generation Matrix (Driessche dan Watmough, 2002) basic reproduction ratio dengan tindakan kontrol $\left(\Re_{0 u}\right)$ adalah

$$
\Re_{0 u}=\frac{c \beta \mu \Lambda}{\mu N(\mu+k)(\mu+r(1+u)+d)} .
$$

Akibatnya dari persamaan (2) $\mathfrak{R}_{0 u} \leq \mathfrak{R}_{0}$. Fungsional objektif pada model kontrol pengobatan optimal pada model tipe SEIT dengan reinfeksi adalah

$$
\min J(u)=\int_{0}^{t_{f}}\left(A I(t)+C u^{2}(t)\right) d t,
$$

dimana $A$ adalah bilangan positif sebagai bobot jumlah individu kompartemen infected, $C$ adalah suatu bobot parameter yang bersesuaian dengan kontrol $u(t)$ dan $t_{f}$ adalah waktu akhir periode.

Langkah pertama untuk mengkaji model kontrol optimal yaitu mencari persamaan Lagrangian dan Hamilton dari masalah kontrol optimal. Persamaan Lagrangian masalah kontrol optimal yaitu:

$$
L(I, u)=A I(t)+C u^{2}(t) .
$$

dibentuk fungsional objektif atau integral indeks performance untuk meminimumkan persamaan Hamilton $H$ dari persamaan (3) dan (5) yaitu:

$$
\begin{aligned}
H= & A I(t)+C u^{2}(t)+\lambda_{1} \frac{d S(t)}{d t}+\lambda_{2} \frac{d E(t)}{d t}+ \\
& \lambda_{3} \frac{d I(t)}{d t}+\lambda_{4} \frac{d T(t)}{d t} .
\end{aligned}
$$


Sebelum menentukan solusi model kontrol optimal, lebih dahulu dikarakterisasi model kontrol seperti yang dinyatakan dalam Teorema 2 berikut:

\section{Teorema 2}

Misalkan $\quad S^{*}(t), \quad E^{*}(t), \quad I^{*}(t), \quad T^{*}(t) \quad$ adalah penyelesaian yang bersesuaian dengan sistem persamaan (6) dan kontrol optimum $u^{*}(t)$ maka terdapat variabel-variabel adjoint $\lambda_{1}, \lambda_{2}, \lambda_{3}, \lambda_{4}$ yang memenuhi:

$\frac{d \lambda_{1}}{d t}=\left(\lambda_{1}-\lambda_{2}\right) \lambda+\lambda_{1} \mu$

$\frac{d \lambda_{2}}{d t}=\left(\lambda_{2}-\lambda_{3}\right)(p \lambda+k)+\lambda_{2} \mu$

$\frac{d \lambda_{3}}{d t}=-A+\left(\lambda_{1}-\lambda_{3}\right) \frac{c \beta S}{N}+\left(\lambda_{2}-\lambda_{3}\right) \frac{p c \beta E}{N}+$

$$
\begin{aligned}
& \left(\lambda_{3}-\lambda_{4}\right)\left(r(1+u)-\frac{\sigma c \beta R}{N}\right)+ \\
& \lambda_{3}(\mu+d)
\end{aligned}
$$

$\frac{d \lambda_{4}}{d t}=\left(\lambda_{4}-\lambda_{3}\right) \sigma \lambda+\lambda_{4} \mu$,

dengan syarat batas (transversality)

$\lambda_{1}\left(t_{f}\right)=\lambda_{2}\left(t_{f}\right)=\lambda_{3}\left(t_{f}\right)=\lambda_{4}\left(t_{f}\right)=0$,

dan kontrol optimum $u^{*}(t)$, yaitu

$u^{*}(t)=\min \left\{b, \operatorname{maks}\left\{a, \frac{\left(\lambda_{3}-\lambda_{4}\right) r I^{*}(t)}{2 C}\right\}\right\}$.

Bukti:

Untuk menentukan persamaan adjoint dan syarat batas, digunakan persamaan Hamiltonian persamaan (6), dengan menggunakan Prinsip Maksimum Pontryagin, diperoleh persamaan adjoint berikut:

$\frac{d \lambda_{1}}{d t}=-\frac{\partial H}{\partial S}, \frac{d \lambda_{2}}{d t}=-\frac{\partial H}{\partial V}, \frac{d \lambda_{3}}{d t}=-\frac{\partial H}{\partial I}$,

$\frac{d \lambda_{4}}{d t}=-\frac{\partial H}{\partial R}$, dengan $\quad \lambda_{1}\left(t_{f}\right)=\lambda_{2}\left(t_{f}\right)=$

$\lambda_{3}\left(t_{f}\right)=\lambda_{4}\left(t_{f}\right)=0 . \quad$ Kondisi optimalisasi

bentuk Hamiltonian terhadap kontrol optimal

$\frac{\partial H}{\partial u_{1}}=2 C u^{*}(t)-\lambda_{3} r I^{*}(t)+\lambda_{4} r I^{*}(t)=0$.

Sehingga diperoleh $u^{*}(t)=\frac{\left(\lambda_{3}-\lambda_{4}\right) r I^{*}(t)}{2 C}$,

dengan menggunakan sifat ruang kontrol

diperoleh

$u^{*}(t)=\left\{\begin{array}{ll}a, & \frac{\left(\lambda_{3}-\lambda_{4}\right) r I^{*}(t)}{2 C} \leq a \\ \frac{\left(\lambda_{3}-\lambda_{4}\right) r I^{*}(t)}{2 C}, & a<\frac{\left(\lambda_{3}-\lambda_{4}\right) r I^{*}(t)}{2 C}<b, \\ b, & \frac{\left(\lambda_{3}-\lambda_{4}\right) r I^{*}(t)}{2 C} \geq b\end{array}\right.$,

atau dapat dituliskan dalam bentuk

$u^{*}(t)=\min \left\{b, \operatorname{maks}\left\{a, \frac{\left(\lambda_{3}-\lambda_{4}\right) r I^{*}(t)}{2 C}\right\}\right\}$.
Solusi dari fungsi adjoint persamaan (7)-(10) yaitu $\lambda_{1}^{*}(t), \lambda_{2}^{*}(t), \lambda_{3}^{*}(t)$, dan $\lambda_{4}^{*}(t)$ yang dapat diperoleh secara numerik.

\section{SIMULASI NUMERIK}

Langkah pertama penyelesaian kontrol optimal dari persamaan (3) dengan memasukkan tebakan awal pada kontrol pengobatan $u^{*}$. Kemudian mensubstitusikan tebakan awal nilai kontrol pada variabel state. Selanjutnya nilai kontrol dan nilai variabel state disubstitusi ke variabel adjoint dengan kondisi transversality. Nilai variabel state dan adjoint disubstitusi kembali ke variabel kontrol, sehingga diperoleh nilai variabel kontrol kedua. Proses ini dilanjutkan sehingga diperoleh nilai variabel state, adjoint, dan kontrol sampai pada waktu akhir yang ditentukan. Simulasi persamaan state dan adjoint diselesaikan dengan metode RungeKutta orde empat skema maju-mundur dengan menggunakan program Matlab. Adapun simbol, deskripsi, dan estimasi parameter dan nilai awal yang digunakan simulasi numerik seperti pada Tabel 1 berikut. Nilai parameter diambil dari jurnal Neilan dan Lenhart (2010), dan nilai $\Lambda$ diasumsikan.

Tabel 1. Simbol, Deskripsi, dan Parameter Model

\begin{tabular}{|c|l|l|}
\hline Simbol & Deskripsi & Estimasi \\
\hline$A$ & Laju rekritmen & $\begin{array}{l}3500 \text { per } \\
\text { tahun }\end{array}$ \\
\hline$c$ & $\begin{array}{l}\text { Tingkat kontak individu } \\
\text { kompartemen } I \text { dengan } \\
\text { individu kompartemen lain }\end{array}$ & $\begin{array}{l}2 \text { per } \\
\text { tahun }\end{array}$ \\
\hline$\beta$ & Laju transmisi infeksi & $\begin{array}{l}14 \text { per } \\
\text { tahun }\end{array}$ \\
\hline$\mu$ & $\begin{array}{l}\text { Laju kematian alamiah } \\
\text { masing-masing } \\
\text { kompartemen }\end{array}$ & $\begin{array}{l}0,01 \text { per } \\
\text { tahun }\end{array}$ \\
\hline$d$ & $\begin{array}{l}\text { Laju kematian kompartemen } \\
\text { terinfeksi karena sakit }\end{array}$ & $\begin{array}{l}0,08 \text { per } \\
\text { tahun }\end{array}$ \\
\hline$k$ & $\begin{array}{l}\text { Laju infeksi aktif dari } \\
\text { infeksi pasif yang tanpa } \\
\text { kontak lagi dengan } I\end{array}$ & $\begin{array}{l}0,2 \text { per } \\
\text { tahun }\end{array}$ \\
\hline$p$ & $\begin{array}{l}\text { Laju infeksi aktif dari } \\
\text { infeksi pasif yang kontak } \\
\text { lagi dengan } I\end{array}$ & $\begin{array}{l}0,3 \text { per } \\
\text { tahun }\end{array}$ \\
\hline$r$ & Laju pengobatan & $\begin{array}{l}0,6 \text { per } \\
\text { tahun }\end{array}$ \\
\hline$\sigma$ & $\begin{array}{l}\text { Laju reinfeksi dari } \\
\text { kompartemen } L \text { ke } I\end{array}$ & $\begin{array}{l}0,12 \text { per } \\
\text { tahun }\end{array}$ \\
\hline
\end{tabular}


Jumlah awal masing-masing kompartemen diasumsikan yaitu: $S(0)=85000, V(0)=10000$, $I(0)=5000, R(0)=0$, sesuai dengan proporsi masing-masing kompartemen suatu populasi pada umumnya. Kontrol pengobatan $1+u(t)$ yaitu upaya mengurangi jumlah individu kompartemen terinfeksi tuberkulosis da meningkatkan jumlah individu komparteme pengobatan.

Pada Gambar 2 dapat dilihat bahwa denga pengobatan dapat menurunkan jumlah individ kompartemen exposed.

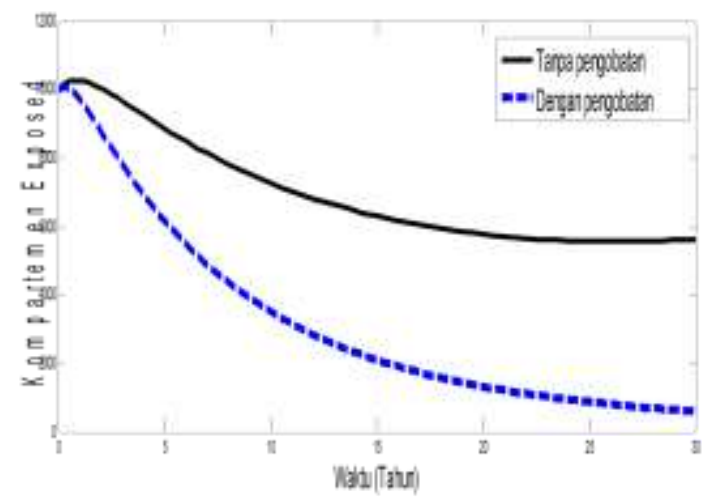

Gambar 2. Dinamika kompartemen exposed dengan pengobatan dan tanpa pengobatan

Pada Gambar 3 dapat dilihat bahwa kontrol pengobatan lebih efektif menurunkan juml ^h individu kompartemen terinfeksi dibandingk dengan tanpa kontrol.

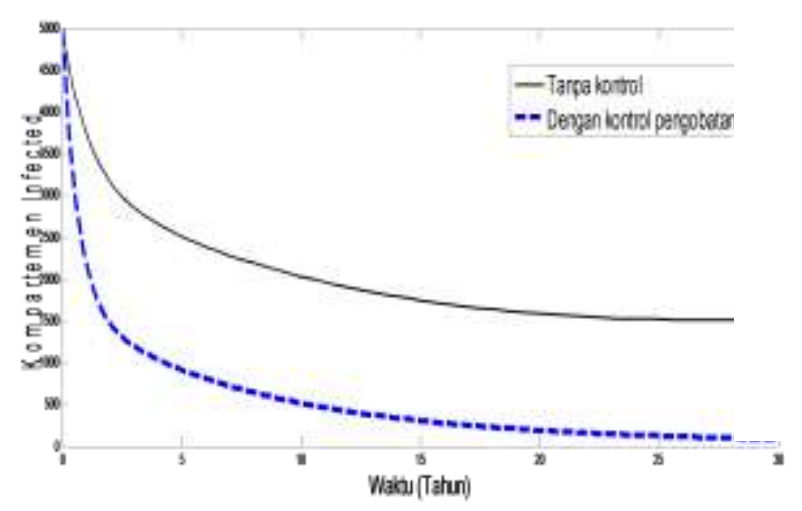

Gambar 3. Dinamika kompartemen terinfeksi dengan kontrol dan tanpa kontrol
Pada Gambar 4 dapat dilihat bahwa kontrol pengobatan lebih efektif meningkatkan jumlah individu kompartemen pengobatan dibandingkan dengan tanpa kontrol.

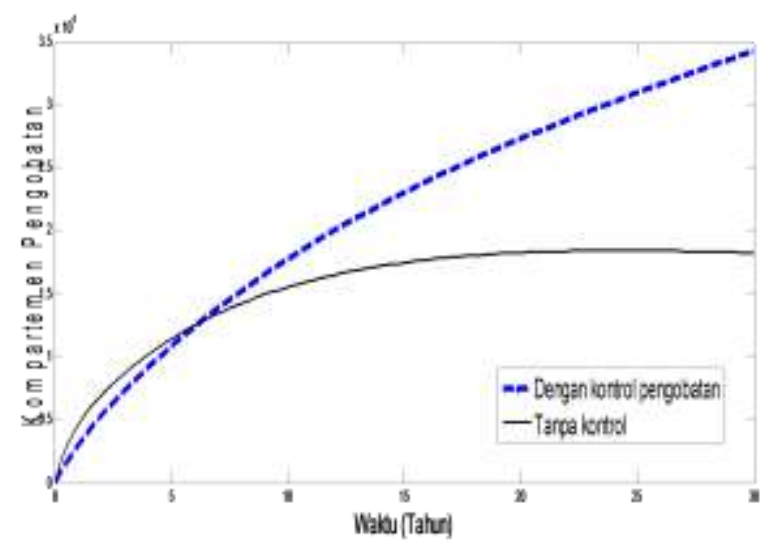

Gambar 4. Dinamika kompartemen pengobatan dengan kontrol dan tanpa kontrol

Pada Gambar 5 dapat dilihat bahwa besarnya biaya kontrol pengobatan tidak mempengaruhi grafik, artinya kontrol pengobatan dengan biaya $C=10$ sudah cukup optimal untuk menurunkan jumlah individu kompartemen terinfeksi atau meningkatkan jumlah individu kompartemen pengobatan.

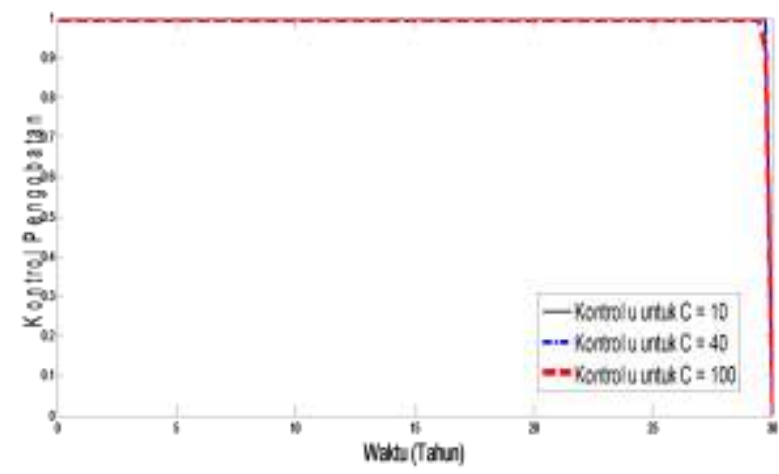

Gambar 5. Kontrol pengobatan dengan $C=10$, $C=40$, dan $C=100$ 


\section{KESIMPULAN}

Berdasarkan kajian model kontrol pengobatan optimal pada model transmisi penyebaran penyakit tuberkulosis tipe SEIT diperoleh bahwa:

1) Pengobatan dapat menurunkan jumlah individu kompartemen exposed.

2) Kontrol pengobatan optimal lebih efektif menurunkan jumlah individu kompartemen terinfeksi dibandingkan dengan tanpa kontrol.

3) Basic reproduction ratio dengan kontrol pengobatan lebih kecil dibandingkan dengan tanpa kontrol artinya kontrol dengan pengobatan lebih efektif menurunkan penyakit tuberkulosis dibandingkan dengan tanpa kontrol.

\section{DAFTAR PUSTAKA}

Agusto, F.B., 2009. Optimal Chemoprophylaxis and Treatment Control Strategies of A Tuberculosis Transmission Model, World journal of modelling and simulation, v.3, no.5, p.163-173.

Bhunu, C.P. et al., 2008. Tuberculosis Transmission Model with Chemoprophylaxis and Treatment, Bulletin of Mathematical Biology,70, p. 1163-1191.

Brauer F. and Castilo-Chavez, C., 2000. Mathematical Model in Population Biology and Epidemiology, Springer.

Castillo-Chavez, C. and Feng, Z., 1997 . To Treat or Not to Treat: The Case of Tuberculosis J. Math. Biol. 35: p. 629-656.

Castillo-Chavez, C. and Song, B., 2004. Dynamical Models of Tuberculosis and Their Applications, Mathematical Biosciences and Engineering, v.1, no.2, p. 361-404.

Crofton, S.J., Horne, M., and Miller, F., 2002. Clinical Tuberculosis, MacMilan Education Ltd, London.

David, S.G., Sant'Anna, C.C., and Marques, A.M., 2000. Antituberculosis chemoprophylaxis in children, Journal de Pediatria, v.76, no.2, p. 109-114.
Driessche, P.v. D. and Watmough, J., 2002. Reproduction Numbers and Sub-Threshold Endemic Equilibria for Compartmental Models of Disease Transmission, Mathematical Biosciences, v. 180, p. 2948.

Gerberding, J. L. et al. 2003. Treatment of Tuberculosis, American Thoracic Society, $C D C$, and Infectious Diseases Society of America, MMWR, v. 52, no. 11.

Manaf, A. dkk., 2007. Pedoman Nasional Penanggulangan Tuberkulosis, Edisi Kedua, Depkes RI.

Neilan, R.M. and Lenhart, S., 2010. An Introduction to Optimal Control with an Application in Disease Modeling, DIMACS Series in Discrete Mathematics, v. 75, p. 67-81.

Perko, L. 1991. Differential Equation and Dynamical Systems, Springer Verlag, New York.

Tchuenche, J. M., Khamis, S. A., Agusto, F. B. and Mpeshe, S. C., 2011. Optimal Control and Sensitivity Analysis of an Influenza Model with Treatment and Vaccination, Acta Biotheor, v. 59, h.1-28.

WHO, 2012. Global Tuberculosis control 2012, WHO Library Cataloguing-in-Publication Data (2011). 